\title{
EXPRESSION OF S-100 PROTEIN, GLIAL FIBRILLARY ACIDIC PROTEIN, NEURON-SPEGIFIC ENOLASE, AND KERATIN IN MIXED TUMORS OF SKIN
}

\author{
Yohko NODA *, Hiroyuki OOSUMI*, Hidemoto HORIKE*, \\ Hiroshi MITANI *, TAKAHIRo TSUJIMURA ** \\ AND MASAHIKo MORI*
}

\author{
Department of Oral Surgery*, Asahi University School of Dentistry, Hozumi, Motosu-gun, \\ Gifu 501-02, and Department of Clinical Pathology **, \\ Sumitomo Hospital, Kita-ku, Osaka 530
}

Received for publication June 26, 1987 and in revised form August 13, 1987

\begin{abstract}
Mixed tumors of sweat gland in the skin were stained by the peroxidase antiperoxidase (PAP) method using antibodies to $S-100$ protein, glial fibrillary acidic protein (GFAP), neuron-specific enolase (NSE), and keratin proteins, in order to evaluate possible histogenesis of the tumors. Secretory coiled cells in normal eccrine glands were moderately positive for S-100 protein, markedly positive for NSE, and negative for GFAP, and they displayed variably intense staining with anti-keratin antibodies. In mixed tumors of the skin, the round, oval or polygonal cells located in the outer zone of tubular or duct-like structures, were usually strongly positive for S-100 protein, gave reactions of varied intensity for NSE, and were generally negative or very weakly positive for GFAP. Spindle-shaped cells were negative or very slightly positive for S-100 protein and strongly positive for NSE; but the reaction for GFAP varied. Tumor cells located on the luminal side of tubular or duct-like structures were uniformly positive for KLl (molecular weight 55-57 Kdaltons keratin) and PKK1 (molecular weight 41-56 Kdaltons keratin). From the present study, it is suggested that mixed tumors of the skin may be differentiated from either transitional portion or myoepithelial cells of the eccrine glands.
\end{abstract}

Mixed tumors of the skin, which are counterparts of pleomorphic adenomas of the salivary glands, may arise from the coiled ductal cells or the myoepithelial cells of the sweat glands. Histologically, tumor cells of myoepithelial origin in mixed tumors of the skin are spindle-shaped and occasionally undergo myxoid or chondroid changes. Transformed or neoplastic myoepithelial cells in pleomorphic adenoma of the salivary gland stain positively for S-100 protein $(3,13,17)$, a protein found in neural tissue and myoepithelial cells. GFAP (4, 21,23) and NSE activity are also found in neural structures as well as in other tissues $(11,12,20)$, particularly in muscle fibers (7). However, immunohistochemical detection of S-100 protein, GFAP, and NSE in mixed tumors of the skin has not been reported yet. 
A comparison was made between the immunohistochemical staining patterns in skin mixed tumors and those of pleomorphic adenoma of the salivary gland which have already been described $(13,17)$. The present study will have histogenesis of mixed tumors in sweat gland origin by using immunohistochemical techniques for the marker of ductal and myoepithelial cells.

\section{MATERIALS AND METHODS}

Specimens of 17 cases of mixed tumors of sweat gland origin, accompanied by normal skin, were obtained from patients under local or general anesthesia. The tissues were fixed in a $10 \%$ formalin solution for $12 \mathrm{hr}$, dehydrated, and embedded in paraffin by routine procedures. Serial paraffin sections of each specimen were cut at $4 \mu \mathrm{m}$ and processed for immunohistochemistry or stained with hematoxyline and eosin for routine light microscopic examination.

Immunohistochemical Methods

1) S-100 protein

For detection of S-100 protein, the PAP method was used. Details of the method are described previously (13).

2) Glial Fibrillary Acidic Protein (GFAP)

After deparaffinization and inactivation of endogenous peroxidase, the indirect immunoperoxidase method was used. The sections were incubated with normal rabbit serum (1:20; JIMRO, Japan) for 30 min to remove nonspecific background staining and then incubated with mouse anti-human glial fibrillary acidic protein antibody (1:5; Monosan, Holland) for 1 hour as the primary anti-serum. The secondary antiserum was HRP-conjugated rabbit anti-mouse IgG (1:20; Dakopatts, Denmark) for 30 min. Finally, 0.03\% 3-3'diaminobenzidine tetrahydrochloride (DAB) containing $0.005 \% \mathrm{H}_{2} \mathrm{O}_{2}$ was used for visualization of the sections.

3) Neuron Specific Enolase (NSE)

The PAP method was used. The sections were treated according to the following steps. For removal of nonspecific staining, they were first immersed in normal swine serum (1:20; Dakopatts, Denmark) for $30 \mathrm{~min}$. The primary antiserum was rabbit anti-human NSE (1:100; Dakopatts, Santa-Barbara, USA) with which the sections were treated for $1 \mathrm{hr}$. Next, swine anti-rabbit IgG (1:20; Dekopatts, Denmark) was applied for $30 \mathrm{~min}$. Then the sections were incubated with peroxidase anti-rabbit IgG (1: 100; Dekopatts, Denmark) for $30 \mathrm{~min}$. Finally, the reaction was visualized by incubation in DAB solution.

4) Monoclonal Keratins

Monoclonal anti-keratin antibodies KLl (Immunotech, France) and PKKl (Labsystems, Finland) were employed to detect keratin protein of various molecular weights (KLl; 55-57 Kdaltons and PKKl; 41-56 Kdaltons). Details of the immunohistocheical procedures have already been described $(8,14,19,22)$.

5) Control Test

Control tissue sections were subjected to the same procedures as the above paraffin sections except that each antigen specific serum was replaced with nonimmunized normal serum, normal rabbit serum for polyclonal and normal mouse serum for monoclonal antibody. The results were negative. 


\section{RESULTS}

\section{Normal Sweat Glands}

The secretory portion of sweat glands contains two different cell types; one is located in the outer zone and is spindle-shaped or branching; and the other type, occuring as a single layer, constitutes the inner lining of coiled duct. The former is myoepithelial; and the latter, secretory portion, consists of round or cuboidal cells. The secretory coiled cells showed moderate staining to S-100 protein, and the transitional portion which is located between secretory and intraepidermal duct areas revealed strong S-100 protein staining, while the myoepithelial cells were negative. Peripheral nerve fibers in the sweat glands showed an intense S-100 protein reaction

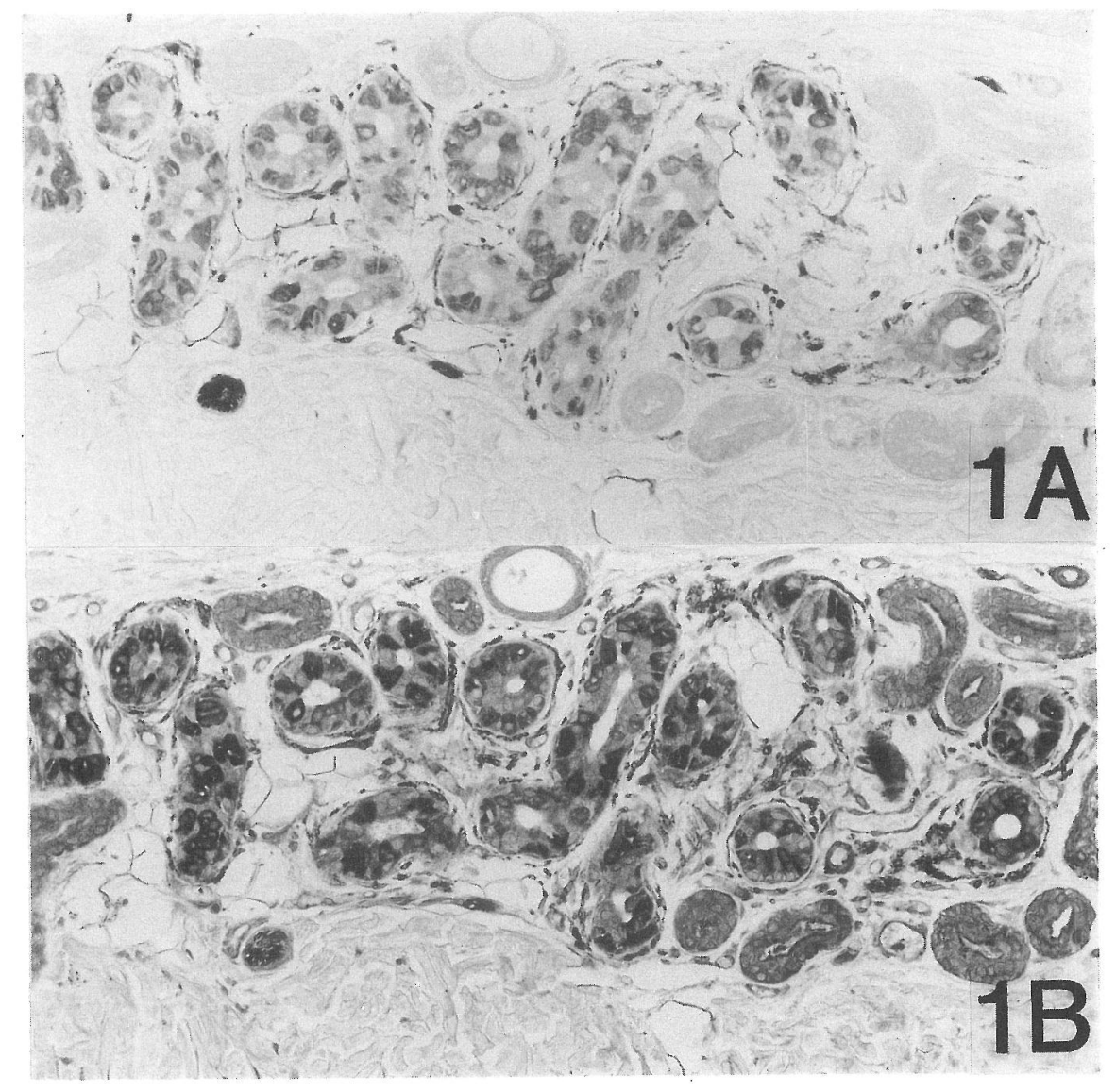

Figs. 1A, B. Normal sweat glands. $\times 100$

FIG. 1A. S-100 protein staining. Moderate staining in secretory coil, strong staining in transitional portion and strong staining in peripheral nerve fibers of the sweat glands.

FIG. 1B NSE staining. Spindle shaped cells in secretory coil and nerve fibers show markedly positive reaction. $\times 100$ 


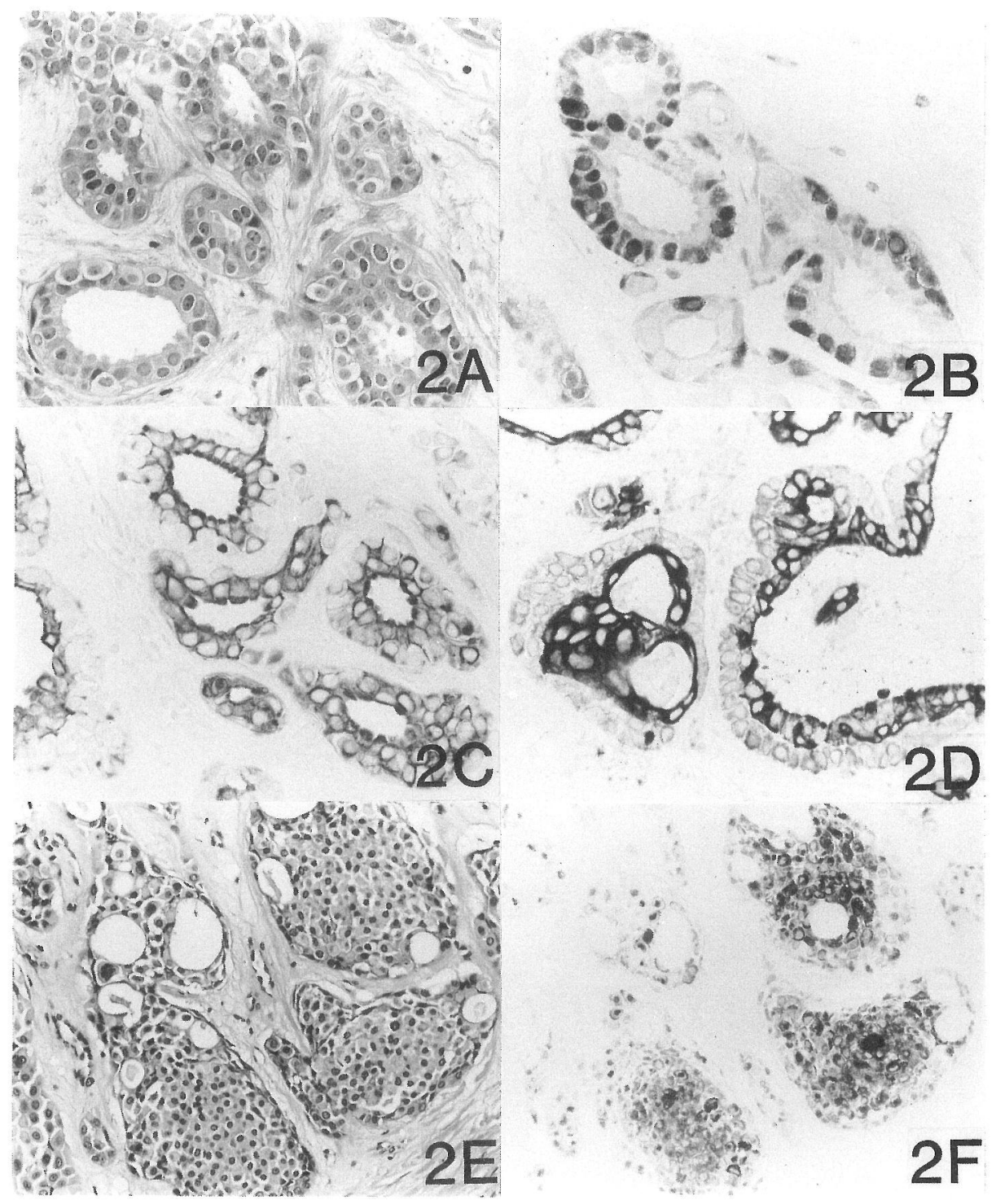

FIGs. 2A-D. Duct-like structure lesion in mixed tumor. $\quad \times 140$

FIG. 2A. H.E. staining. The duct-like structures are composed of double or more layer cells of which the luminal side is flat shape and the outer is round or cuboidal in shape.

FIG. 2B. S-100 protein staining. The outer layered cells contain strong positive reaction.

FIG. 2C. PKKl keratin staining. The inner layered cells are moderately reactive.

FIG. 2D. KLl staining. The inner layered cells are strongly positive.

Figs. 2E-F. Solid tumor foci in the mixed tumor. $\times 70$

FIG. 2E. H.E. staining.

FIG. 2F. S-100 protein staining. Solid structures are composed of round or polyhedral eosinophilic cells showing strong $\mathrm{S}-100$ protein staining. 


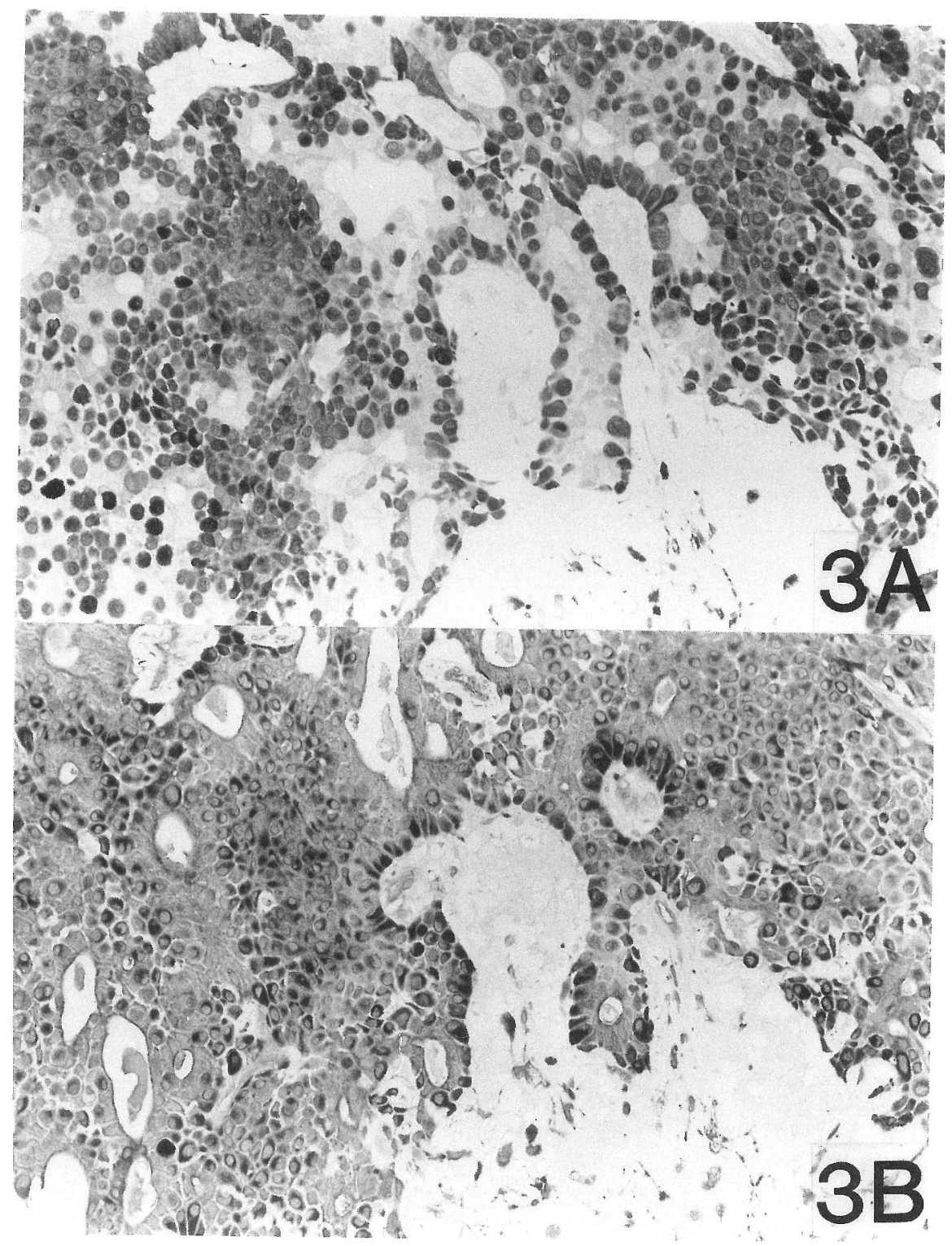

FIGs. 3A, B. Strand and cord structure lesion in the mixed tumor. $\times 100$

FIG. 3A. S-100 protein staining.

FIG. 3B. NSE staining. The peripheral tumor cell zones are composed of round cells. S-100 protein is positive in round tumor cells, and NSE staining is also positive in the cells. 
(Fig. 1A). NSE staining was abundant in coiled duct cells of the terminal portion (Fig. 1B) along with positive S-100 protein staining. Nerve fibers were also markedly positive for NSE. GFAP staining in sweat glands was absent, except for nerve fibers. Keratin distribution in sweat glands was usually strong in luminal layer cells of dermal and epidermal duct for all the keratins (detected with $\mathrm{KLl}$ and $\mathrm{PKKl}$ ), while staining was slight or very low in myoepithelial cells.

Mixed Tumors of the Skin

Histologic aspects of mixed tumors of sweat gland origin essentially resembled those of salivary gland origin. The tumor cells were arranged in cords, strands or solid masses, and cystic formation was varied in size. Clear cell alteration was also found. As the typical structure of these mixed tumors, tubular or duct-like structures were generally composed of a double layer or more of tumor cells (Fig. 2A). Also in typical structures, some of the outer layer tumor cells had spindle-shaped or long fibrillar processes cells.

1. Tubular and duct-like structures

S-100 proteins were confined to the clear type cells located on the outer side, and staining intensity was generally strong (Fig. 2B), whereas the luminal sie cells of the flat or cuboidal in shape were negative. The staining reactions for GFAP and NSE were usuall slight or negative; particularly, GFAP staining was very minimal in these structures. Keratin proteins ( $\mathrm{KLl}, \mathrm{PKKl})$ were limited to luminal layer cells with the degree of $\mathrm{KLl}$ moderate and $\mathrm{PKKl}$ strong (Figs. 2C, D).

\section{Solid structure}

Solid structures in the mixed tumors were composed mostly of round or polyhedral eosinophilic cells in the central focus (Fig. 2E). S-100 protein staining was particularly strong and restricted to these cells (Fig. 2F). However, peripheral cells of flat or cuboidal shape did not show strong S-100 protein reaction. GFAP and NSE staining reactions were not strong in those tumors. The clear cell variant of skin mixed tumors was occasionally observed. S-100 protein staining in such regions was also positive with slight to moderate intensity. The PKKl staining was moderate, whereas the KLl staining was strong and their distribution was scattered.

3. Strand or cord structures

There were two types of histologic features in peripheral tumor cell zones of strand or cord structures, i.e., round or oval tumor cells and spindle shaped tumor cells. These two different types of peripheral tumor cells showed dissimilar staining patterns of immunohistochemically detectable S-100 protein and NSE. Round tumor cells were usually intensely positive for S-100 protein and NSE as well as for keratin proteins, while they were negative for GFAP (Figs. 3A, B). In contrast, the spindleshaped tumor cells exhibited weak staining for S-100 protein and keratins (KLl and PKKl), though they were also intensely positive for NSE and gave a weak GFAP reac-

Figs. 4A-C. The lesion of cord and solid structure in the mixed tumor. $\quad \times 100$

Fig. 4A. S-100 protein staining. S-100 protein staining is confined to limited tumor cells located in the solid focus.

FIG. 4B. GFAP staining. Most neoplastic cells show positive staining to GFAP, and some tumor cells also indicate strongly positive to GFAP as well as S-100 protein.

FIG. 4C. NSE staining. Spindle tumor cells located outer zone of cord structure display strongly positive staining to NSE reaction. Heterogenity of immunohistochemical localization of S-100 protein, GFAP and NSE is given in the tumor cells. 


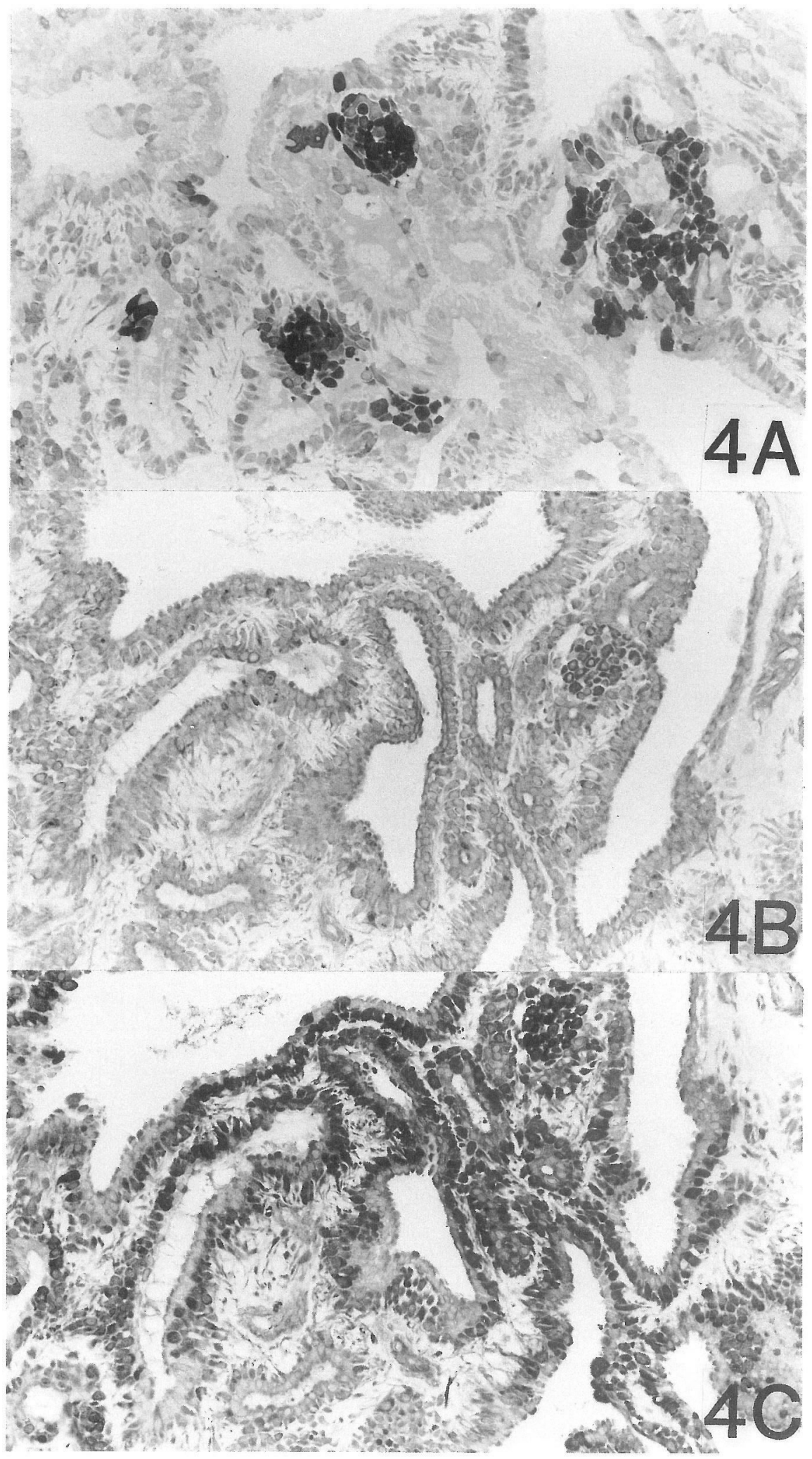


TABLE 1. Immunohistochemical distribution of S-100, NSE, GFAP KLl and PKKl in mixed tumor and normal sweat gland

\begin{tabular}{|c|c|c|c|c|c|}
\hline & S-100 & NSE & GFAP & KLl & PKKl \\
\hline \multicolumn{6}{|l|}{ Normal sweat gland } \\
\hline coiled duct & \pm-1 & \pm-3 & 0 & 0 & 0 \\
\hline epidermal and dermal duct & \pm & 2 & 0 & 2 & 2 \\
\hline transitional cell & 3 & 3 & 0 & $1-2$ & $1-2$ \\
\hline myoepithelial cell & 0 & 1 & 0 & \pm & \pm \\
\hline nerve fiber & 3 & 3 & 3 & 0 & 0 \\
\hline \multicolumn{6}{|l|}{ Duct-like structure } \\
\hline outer side & $2-3$ & \pm & \pm & 0 & 0 \\
\hline inner side & 0 & \pm & \pm & 2 & 2 \\
\hline Solid structure & $\begin{array}{c}1-2 \\
\text { (periphery: } 0 \text { ) }\end{array}$ & $0- \pm$ & $0- \pm$ & $\begin{array}{c} \pm-3 \\
\text { (scatter) }\end{array}$ & $\begin{array}{c} \pm-2 \\
\text { (scatter) }\end{array}$ \\
\hline \multicolumn{6}{|l|}{ Strand structure } \\
\hline round cell & $2-3$ & $1-2$ & \pm-1 & $\begin{array}{c}1-2 \\
\text { (scatter) }\end{array}$ & $\begin{array}{c}1-2 \\
\text { (scatter) }\end{array}$ \\
\hline spindle cell & \pm & $1-2$ & \pm & $0- \pm$ & $0- \pm$ \\
\hline Fibrillar cell & 1 & \pm & 0 & 0 & 0 \\
\hline Clear cell & \pm-1 & 0 & 0 & 0 & 0 \\
\hline
\end{tabular}

$0:$ negative, $\pm:$ trace, 1 : slight, 2 : moderate, 3 : strong

tion. In the tumor specimens showing a typical feature of histology, round, oval and polyhedral tumor cells located into neoplastic focus showed abundant staining to S100 protein, and NSE, and moderate-to-strong staining to GFAP (Figs. 4A-C).

The incidence of S-100 protein-positive cells in mixed tumors of the skin was not always the same; however, S-100 protein-positive tumor cells were usually also positive for NSE staining, but were generally negative or very weak for GFAP staining. Peripheral tumor cells which displayed round, oval or cuboidal shapes contained an abundance of S-100 protein, as well as varying amounts of NSE. On the contrary, peripheral tumor cells of the spindle or anastomosing type were negative or very slightly positive for S-100 protein and GFAP, and they were strongly positive for NSE (Table 1).

\section{DISCUSSION}

It has been reported that nerve fibers and nerve tissues $(4,12)$ as well as myoepithelial cells of salivary glands $(16,17)$ and sweat glands $(15)$ generally contain S-100 proteins. Modified and transformed myoepithelial cells in salivary gland pleomorphic adenomas also give a positive reaction for $\mathrm{S}-100$ proteins $(2,13,16,17)$, and conversely, the S-100 protein is not confined to myoepithelial cells of normal 
salivary gland $(1,2,13)$. The normal myoepithelial cells of eccrine gland gave the negative reaction, whereas the modified myoepithelial cells showed positive reaction in skin mixed tumor. NSE or $\alpha$-enolase is present in both neural structures $(12,18,20)$ and myoepithelial cells are in mammary, sweat, and parotid glands as well as in smooth muscle elements (7). GFAP is immunologically related to central and peripheral nervous systems $(4,21)$ and is bound to the low molecular weight filaments (23).

Morphologically some structures in mixed tumors of the skin also resembled those of salivary plemorphic adenoma, although there was some differences. Basically, the two neoplastic lesions are composed of tubular or ductal epithelial cells and modified myoepithelial cells. And the former shows positive keratin staining, while the latter may be positive for S-100 protein, and for other nerve or glial-associated proteins or NSE. It is interesting to note that modified or neoplastic myoepithelial cells specifically contained S-100 protein, NSE, and GFAP, however, not all of such cells reacted positively. Heterogeneity of S-100 protein, NSE, and GFAP localization was related to the histologic features. Tubular and duct-like structures, one typical histological pattern seen in both mixed tumors of the skin and salivary glands, usually consisted of a double cell layer or more. These outer layer cells, which were similar to myoepithelial cells morphologically, were round, oval or polygonal in shape with a plump appearance and were characterized by marked S-100 protein staining (13). Their staining reaction to NSE was varied and there was no evidence of GFAP or keratin staining. Another typical neoplastic myoepithelial cell was the spindle or dendrical cell which was also located in the outer layer of tubular and duct-like structures. However, this type showed no or just slight staining for S-100 protein and GFAP, and intense staining for NSE. Thus, these two different types of neoplastic myoepithelial cells of mixed tumors of sweat gland origin characteristically showed different expressions of S-100 protein, NSE, and GFAP.

Mixed tumors of the skin occasionally displayed chondroidal or osteochondroidal changes, as evidenced by long spindle or dendrical cells of myoepithelial origin. Chondrocytes are known to be positive for S-100 protein (15), as are such cells in pleomorphic adenomas of salivary glands $(13,16)$. Nakazato et al. (17) stated that fibrillar tumor cells in the matrix of myxomatous area of salivary pleomorphic adenomas were positive for GFAP staining; whereas in the present study, no marked reaction indicating GFAP was given by fibrillar cells or spindle cells with long processes in mixed tumors of sweat glands, irrespective of positive S-100 protein staining.

In the present immunohistochemical study, a normal eccrine sweat gland was divided into 3 parts; secretory portion as coiled duct, transitional portion between secretory portion and intra-epidermal duct, and intra-epidermal and dermal duct. Transitional portion of eccrine sweat gland possibly corresponded to intercalated duct which is located between acinar cells and striated duct in the salivary gland. Histogenesis of mixed tumors of the skin can involve three different cell types: coiled duct or terminal portion cells, transitional and myoepithelial cells. Thus, homologous cells of mixed tumors of the skin may continue to grow either as cells in secretory portion or transitional portion and as myoepithelial cells. However, modified or neoplastic, transitional and myoepithelial cells in mixed tumor of the skin contain or express S-100 protein, NSE, and GFAP, although not all such cells in tumor lesions react positively. During transformation of normal sweat glands, the 
histochemical properties of the cells may change to be more neuron-specific in nature.

Myoepithelial cells are known to contract and to promote secretory functions from acinar or terminal secretory structures, and actin protein has been detected in tumors $(5,10)$. On the contrary, the biological properties of modified or neoplastic myoepithelial cells in tumor lesions, may have changes to those of myofibrous elements combined with epithelial characteristics, as evidenced by positive reactions for vimentin, desmin and keratin proteins (6). Hori et al. (9) stated that myofilaments containing actin and myosin represent a completely independent filament system from filaments containing keratin and that myoepithelial cells of sweat glands are derived from the ectoderm. In this present study, it was suggested that the mixed tumors of the skin can possibly be differentiated from both transitional portion and myoepithelial cells, however their exact orgin is still unclear.

\section{REFERENCES}

1. Abenoza, P. and Wick, M. R.: Acinic cell carcinoma of salivary glands: An immunohistochemical study. Lab. Invest. 52; 1A, 1985.

2. Abenoza, P. and Wick, M. R.: Immunohistochemistry of common salivary gland tumors. Lab. Invest. 54; 1A, 1986.

3. Batsakis, J. G., Ordonez, N. G., Meis, R. J. and Brune, J. M.: S-100 protein and myoepithelial neoplasms. J. Laryngol. Otol. 100; 687-698, 1986.

4. Bishop, A. E., Carlei, F., Lee, V., Trojanowski, J., Marangos, P. J., Dahl, D. and Polak, J. M.: Combined immunostaining of neurofilaments, neuron specific enolase, GFAP and S100 protein. A possible means for assessing the morphological and functional status of the enteric nervous system. Histochemistry 82; 93-97, 1985.

5. Caselitz, J., Loning, T., Staquet, M. J., Seifert, G. and Thivolet, J.: Immunohistochemical demonstration of filamentous structures in the parotid gland; occurrence of keratin and actin in normal and tumoral parotid gland with special respect to the myoepithelial cells. Cancer Res. Clin. Oncol. 100; 59-68, 1981.

6. Caselitz, J., Osborn, M., Seifert, G. and Weber, K.: Intermediate-sized filament protein (prekeratin, vimentin, desmin) in the normal parotid gland and parotid gland tumors. Immunofluorescence study. Virchows Arch. (Pathol. Anat.) 393; 273-286, 1981.

7. Haimoto, H., Takahashi, Y., Koshikawa, T., Nagura, H. and Kato, K.: Immunohistochemical localization of $\alpha$-enolase in normal human tissues other than nervous and neuroendocrine tissues. Lab. Invest. 52; 257-263, 1985.

8. Hölthofer, H., Miettinen, A., Passivuo, R., Lehto, V. P., Liber, E., Alfthan, O. and Virtanan, I.: Cellular origin and differentiation of renal carcinomas. A fluorescence microscopic study with kidney-specific antibodies, antiintermediate filament antibodies and lectins. Lab. Invest. 49; 317-326, 1983.

9. Hori, K., Hashimoto, K., Eto, H. and Dekio, S.: Keratin type intermediate filaments in sweat glands myoepithelial cells. J. Invest. Dermatol. 85; 453-459, 1985.

10. Hosaka, M., Tatemoto, Y., Yamagami, T., Hikosaka, N. and Mori, M.: Immunohistochemical evaluation of different filament proteins in human salivary glands. Acta histochem. cytochem. 18; 505-515, 1985.

11. Inoue, M., Ueda, G. and Nakajima, T.: Immunohistochemical demonstration of neuronspecific enolase in gynecologic malignant tumors. Cancer 55; 1686-1690, 1985.

12. Matsunou, H., Shimoda, T., Kakimoto, S., Yamashita, H., Ishikawa, E. and Mukai, M.: Histopathologic and immunohistochemical study of malignant tumors of peripheral nerve sheath (malignant schwannoma). Cancer 56; 2269-2279, 1985. 
13. Mori, M., Murase, N., Hosaka, M. and Orito, T.: Immunohistochemical expression of S-100 protein in reactive and neoplastic myoepithelial cells of variant salivary plemorphic adenomas. Acta histochem. cytochem. 19; 231-240, 1986.

14. Mori, M., Sumitomo, S., Iwai, Y. and Meenaghan, M. A.: Immunolocalization of keratins in salivary gland pleomorphic adenoma using monoclonal antibodies. Oral Surg. 61; 611-616, 1986.

15. Nagano, H., Kageshita, T. and Ono, T.: Immunohistochemical and ultrastrutural studies of mixed tumor of the skin. Jpn. J. Dermatol. 96; 629-636, 1986.

16. Nakazato, Y., Ishizeki, J., Takahashi, K., Yamaguchi, H., Kamei, T. and Mori, T.: Localization of S-100 protein and glial fibrillary acidic protein related antigen in pleomorphic adenoma of the salivary glands. Lab. Invest. 46; 621-626, 1982.

17. Nakazato, Y., Ishida, T., Takahshi, K. and Suzuki, K.: Immunohistochemical distribution of S-100 protein and glial fibrillary acidic protein in normal and neoplastic salivary glands. Virchows Arch. (Pathol. Anat.) 405; 299-310, 1985.

18. Sasaki, A., Ogawa, A., Nakazato, Y. and Ishida, Y.: Distribution of neurofilament protein and neuron-specific enolase in peripheral neuronal tumours. Virchows Arch. (Pathol. Anat.) 407; 33-41, 1985.

19. Schlegel, R., Banks-Schlegel, S. and Pinkus, G. S.: Immunohistochemical localization of keratin in normal human tissues. Lab. Invest. 42; 91-96, 1980.

20. Simpson, S., Vinik, A. I., Marangos, P. J. and Lloyd, R. V.: Immunohistochemical localization of neuron-specific enoloase in gastroenteropancreatic neuroendocrine tumors. Correlation with tissue and serum levels of neuron-specific enolase. Cancer 54; 1364-1369, 1984.

21. Tascos, N. A., Parr, J. and Gonatas, N. K.: Immunohistochemical study of the glial fibrillary acidic protein in human neoplasms of the central nervous system. Hum. Pathol. 13; 454-458, 1982.

22. Viac, J., Reano, A., Brochier, J. and Staquet, M. J.: Reactivity pattern of a monoclonal antikeratin antibody (KLl). J. Invest. Dermatol. 81; 351-354, 1983.

23. Yen, S.-H. and Fields, K. L.: Antibodies to neurofilament, glial filament, and fibrobalst intermediate filament proteins bind to different cell types of the nervous system. J. Cell Biol. 88; 115-126, 1981. 